\title{
ATIVIDADE ENZIMÁTICA E PARAMÊTROS FISICO-QUÍMICOS DE ÁGUA DE COCOS COLHIDOS EM DIFERENTES ESTÁDIOS DE DESENVOLVIMENTO E ESTAÇÃO CLIMÁTICA ${ }^{1}$
}

\author{
ANGELA KWIATKOWSKI ${ }^{2}$, DALANY MENEZES OLIVEIRA ${ }^{3}$, EDMAR CLEMENTE ${ }^{4}$
}

RESUMO - Nos últimos anos, agricultores da região noroeste do Paraná vêm cultivando o coqueiro, visando à comercialização da água do fruto verde. Na literatura, ainda são poucos os relatos sobre as características da água de coco verde na região. Assim, o objetivo deste trabalho foi avaliar os aspectos físico-químicos e a atividade das enzimas peroxidase (POD) e polifenoloxidase (PPO) da água de coco, cv. Anão-Verde, de frutos colhidos em diferentes estádios de desenvolvimento e estações climáticas. Os frutos foram colhidos no município de Umuarama, Paraná, nas quatro estações climáticas e em cinco estádios de desenvolvimento. Foram realizadas avaliações da atividade da POD e PPO, turbidez, pH, acidez titulável (AT), compostos fenólicos e teores de minerais da água de coco. As atividades da PPO e da POD apresentaram os maiores valores no inverno, variando de 1,87 a $3,69 \mathrm{U} \mathrm{mL}^{-1}$ para PPO e 15,42 a 22,56 $\mathrm{U} \mathrm{mL}^{-1}$ para POD. A turbidez variou de 10,14 a 15,16 NTU, sendo valor referente à água de coco colhido com sete meses e nove meses na primavera. AAT resultou em valores entre 0,057 e $0,113 \mathrm{~g}$ de ácido cítrico $100 \mathrm{~mL}^{-1}$. No inverno e na primavera, a água de coco apresentou os maiores valores de compostos fenólicos em relação às outras estações. O potássio foi o mineral presente em maior concentração em todas as amostras. Os parâmetros avaliados indicam que a água de coco produzida em Umuarama, Paraná, apresenta características bioquímicas e físicoquímicas adequadas e semelhantes aos cocos produzidos em regiões tropicais.

Termos de indexação: Cocos nucifera L., cv. Anão-Verde, enzimas, turbidez, compostos fenólicos.

\section{ENZYMATIC ACTIVITY AND PHYSICOCHEMICAL PARAMETER OF COCONUT WATER OF FRUIT HARVESTED ON DIFFERENT STAGES OF DEVELOPMENT AND CLIMATE SEASONAL}

\begin{abstract}
In recent years, farmers in the northwest of Paraná have been cultivating coconut tree, seeking for commercialization of water of the green fruit. In literature there are few reports on the characteristics of green coconut water in the region. Thus, the purpose of this study was to evaluate the physicochemical aspects and activities of peroxidase (POD) and polyphenoloxidase (PPO) of coconut water, cv. Dwarf Green, from fruits harvested at different developmental stages and climate seasonal. The fruits were harvested in Umuarama, Paraná, in the four seasons and in five stages of development. The activity of POD and PPO, turbidity, $\mathrm{pH}$, acidity (TA), phenolic compounds and mineral contents of coconut water were evaluated. The activities of PPO and POD showed the highest values in winter, ranging from 1.87 to $3.69 \mathrm{U} \mathrm{mL}^{-1}$ to PPO and 15.42 to $22.56 \mathrm{U} \mathrm{mL}^{-1}$ to POD. Turbidity ranged from 10.14 to $15.16 \mathrm{NTU}$, and values relative to coconut water collected with seven months and nine months in the spring. The TA resulted in values between 0.057 and $0.113 \mathrm{~g}$ citric acid $100 \mathrm{~mL}^{-1}$. In the winter and in the spring, coconut water had the highest values of phenolic compounds in relation to other climate seasons. Potassium was the mineral found in highest concentration in all samples. The parameters indicate that the coconut water produced in Umuarama, Paraná, has the biochemical and physicochemical appropriate and similar to coconuts produced in tropical regions. Index terms: Cocos nucifera L., Anão Verde cv., enzymes, turbidity, phenolic compouds.
\end{abstract}

\footnotetext{
1(Trabalho 170-11). Aceito para publicação em: 27-05-2011. Recebido em: 10-04-2012.

${ }^{2}$ Mestre em Agronomia, Doutoranda em Agronomia, Universidade Estadual de Maringá (UEM), Av. Colombo, 5790, CEP. 87020-900, Maringá- PR. E-mail: angelak.k@gmail.com

${ }^{3}$ Mestre em Agronomia, Doutoranda em Ciência de Alimentos, Universidade Estadual de Maringá (UEM), Av. Colombo, 5790, CEP. 87020-900, Maringá- PR. E-mail: dalany5@yahoo.com.br

${ }^{4} \mathrm{Ph} . \mathrm{D}$. em Ciência de Alimentos, Prof. do Departamento de Química, Universidade Estadual de Maringá (UEM), Av. Colombo, 5790, CEP. 87020-900, Maringá- PR. E-mail: eclemente@uem.br
} 


\section{INTRODUÇÃO}

A formação da água de coco é uma estratégia ecofisiológica do coqueiro para armazenar substâncias nutritivas de reservas que serão utilizadas como mecanismo de sobrevivência da espécie. A água de coco começa a se formar dois meses depois do fenômeno da fertilização (ARAGÃO et al., 2005) e passa por mudanças em sua composição durante o desenvolvimento do fruto que podem ser influenciadas por fatores como: temperatura na estação de cultivo, intensidade de radiação solar, chuvas, classe de solo e tratos culturais (CABRAL et al., 2005; MACIEL et al., 2009).

As transformações bioquímicas, são os principais eventos responsáveis pelas modificações nos atributos sensoriais e vida de prateleira dos frutos. Assim, a avaliação da atividade enzimática é uma forma de monitoramento da qualidade pós-colheita, principalmente frente às modificações bioquímicas, como indicadoras do grau de frescor e conservação. Entre essas enzimas podem ser citadas as polifenoloxidases (PPO) e peroxidases (POD). As PPOs são capazes de oxidar compostos fenólicos com o auxílio do oxigênio molecular. A síntese de compostos fenólicos está relacionada ao mecanismo de defesa da planta (RUENROENGKLIN et al., 2009; REICHEL et al., 2010). O resultado final das reações catalisadas por essas enzimas são quinonas, substâncias que se combinam entre si, e outros componentes do meio para formar produtos de condensação de alta massa molecular e cor escura, as melaninas. Este processo é chamado de escurecimento enzimático e é indesejável por alterar o sabor, o odor e o valor nutricional. Nas frutas, o teor de PPO aumenta com a maturação e a senescência (PENHA et al., 2005).

As PODs são capazes de oxidar diferentes compostos, na presença de peróxidos, gerando radicais livres. Seu substrato principal é o peróxido de hidrogênio $\left(\mathrm{H}_{2} \mathrm{O}_{2}\right)$, embora possam atuar sobre fenóis e aminas aromáticas. As PODs podem, na ausência de peróxidos, catalisar a oxidação de alguns substratos com auxílio do oxigênio molecular. Os efeitos da POD em água de coco são semelhantes aos da PPO, e muitas vezes confundidos. Os aspectos físico-químicos, como acidez, turbidez, compostos fenólicos e teor de minerais da água de coco, devem ser sempre avaliados, pois estão relacionados com o desenvolvimento das reações enzimáticas indesejáveis (DUARTE et al., 2002; PENHA et al., 2005).

Na região noroeste do Estado do Paraná, nos últimos 17 anos, os agricultores têm introduzido a cultura do coqueiro Anão-Verde em escala comercial. Os agricultores visam a abastecer mercados do Sul e Sudeste do Brasil (KWIATKOWSKI et al., 2008). Em 2008, o Paraná produziu 905 mil frutos, 100\% da produção de coco da região Sul (IBGE, 2008). Entretanto, ainda são poucas as informações sobre as características da água de coco produzida nesta região. Assim, o objetivo deste trabalho foi avaliar a atividade da PPO e POD e os aspectos físico-químicos da água de coco, cv. Anão-Verde, produzidos em Umuarama, Paraná, colhidos em diferentes estádios de desenvolvimento e estação climática.

\section{MATERIAIS E MÉTODOS}

Foram avaliadas as águas de cocos (Cocos nucifera L.), cv. Anão-Verde, em cinco estágios de desenvolvimento, 5; 6; 7; 8 e 9 meses após a fecundação, produzidos em Umuarama, Paraná. Foram realizadas colheitas nas quatro estações climáticas do período 2009/2010. As colheitas foram realizadas ao final de cada estação climática, sendo iniciada com a estação de inverno/2009 e finalizada com outono/2010. A unidade experimental em campo foi composta de 16 plantas, com quatro blocos ao acaso.

No município de Umuarama, a área totalizada da cultura de coco é de aproximadamente 1,5 ha, sendo representada por 960 plantas. O plantio do coqueiro é em linha, com espaçamento de 7,0 m entre as plantas. A cultura foi implantada há cerca de dez anos. O cultivo dos coqueiros segue o método convencional sem irrigação. Segundo a classificação de Köeppen, o clima da região é caracterizado por clima subtropical úmido, com verão quente, $\mathrm{Cfa}$ (h), sendo h, clima tropical modificado pela altitude. As temperaturas são superiores a $22^{\circ} \mathrm{C}$ no verão e com mais de $30 \mathrm{~mm}$ de chuva no mês mais seco.

O solo do município de Umuarama é classificado como Latossolo Vermelho distrófico típico de textura arenosa, e está localizado na região noroeste do Paraná, a $480 \mathrm{~m}$ acima do nível do mar, entre a Latitude $23^{\circ} 44^{\prime}$ Sul e Longitude $53^{\circ} 17^{\prime}$ Oeste. Foram realizadas análises do solo da área demarcada pela copa e pela entrelinha da cultura. O solo foi colhido com coletor sendo 0-20 e 20-40 cm de profundidade, tanto para a área da copa quanto para a entrelinha. Foram retiradas amostras de doze pontos da cultura. Os solos das áreas estudadas foram coletados no dia da primeira colheita dos frutos, e suas características podem ser observadas na Tabela 1 .

$\mathrm{O}$ delineamento experimental utilizado foi o de blocos inteiramente casualizados. Foram avaliados quatro blocos de campo formados por doze plantas. Foram colhidos 12 frutos de cada estádio de desenvolvimento por bloco, e as avaliações físico-químicas e enzimáticas foram realizadas em triplicata. As datas 
das colheitas podem ser visualizadas na Tabela 2 .

As determinações de turbidez das águas de cocos foram realizadas em turbidímetro digital. Os resultados foram expressos em NTU (Nephelometric Turbidity Unit). $\mathrm{O} \mathrm{pH}$ da água dos frutos foi avaliado com o auxílio de potenciômetro digital. A avaliação de acidez titulável (AT) foi realizada de acordo com a metodologia do Instituto de Tecnologia de Alimentos - ITAL (1990).

Os teores de compostos fenólicos foram determinados conforme Bucic-Kojic et al. (2007), utilizando solvente etanol a $50 \%$ e o reagente de Folin-Ciocalteau. A leitura foi realizada em espectrofotômetro UV/Vis a $756 \mathrm{~nm}$. O branco foi preparado com água destilada em substituição ao extrato etanólico. A calibração da curva foi realizada com ácido gálico.

Os componentes minerais da água dos frutos foram quantificados no Laboratório de Agroquímica da Universidade Estadual de Maringá, por meio de digestão nitroperclórica, sendo cálcio $(\mathrm{Ca})$, magnésio $(\mathrm{Mg})$, potássio $(\mathrm{K})$, fósforo $(\mathrm{P})$, sódio $(\mathrm{Na})$, manganês $(\mathrm{Mn})$, ferro $(\mathrm{Fe})$, cobre $(\mathrm{Cu})$ e zinco $(\mathrm{Zn})$ Essas determinações foram realizadas pelo método de espectrofotometria de absorção atômica (Varian - 10 Plus), e para a determinação de P foi utilizado o método descrito por Pavan et al. (1992), por meio de espectrofotometria de UV-VIS (Hitachi - 2001).

Foram realizadas determinações da atividade das enzimas polifenoloxidase (PPO) e peroxidase (POD) da água de coco, conforme Abreu e Faria (2007), por meio de espectrofotômetro UV/Vis a $425 \mathrm{~nm}$ para PPO e $470 \mathrm{~nm}$ para POD, no tempo zero e após 10 minutos. Utilizou-se como branco a mistura de todos os reagentes, substituindo-se a água de coco por água destilada. A atividade foi expressa em unidades/mL.minuto.

Os resultados foram avaliados estatisticamente por meio da Análise de Variância (ANOVA), e as médias foram comparadas pelo teste de Tukey, a 5\% de probabilidade, com auxílio do programa estatístico Statistical Analisys System (SAS, 2001).

\section{RESULTADOS E DISCUSSÃO}

Os resultados da avaliação da atividade das enzimas PPO e POD da água de coco podem ser observados na Figura $1 \mathrm{~A}$ e 1B, respectivamente. Ambas as atividades enzimáticas aumentaram conforme aumento do tempo de desenvolvimento dos frutos. Para as duas enzimas, a maior atividade foi determinada na colheita realizada no final do período de inverno e menor para a água colhida ao término das estações verão e outono.
Pode ser observado que a atividade da PPO resultou em 2,24 $\mathrm{U} \mathrm{mL}^{-1}$ quando colhido com cinco meses e apresentou valor de $3,69 \mathrm{U} \mathrm{mL}^{-1}$ aos nove meses de desenvolvimento, com aumento de $64,73 \%$, na estação de inverno. Os frutos que foram colhidos no final da primavera apresentaram variação da atividade da água de coco de 2,10 a 3,08 $\mathrm{U} \mathrm{mL}^{-1}$ (de cinco a nove meses de idade), com diferença estatística $(\mathrm{p}<0,05)$ para o último valor, com nove meses.

Na colheita realizada ao término do verão, obteve-se valor de aumento da atividade da PPO, de $54,55 \%$, e a água avaliada no final do outono, de $37,91 \%$ para frutos colhidos de cinco a nove meses. A PPO é uma enzima que atua sobre grande variedade de compostos fenólicos, em função do $\mathrm{pH}$ do meio, concentração de compostos fenólicos presentes, temperatura, concentração da própria enzima, entre outros fatores. Assim, podemos relacionar os teores de compostos fenólicos com a atividade enzimática e formação de quinonas, sendo este o primeiro sinal de resposta fisiológica quando ocorrem danos aos tecidos ou ataque de patógenos, e possuem propriedades antimicrobianas efetivas (CONCELLÓN et al., 2004).

A atividade da POD também apresentou aumento na atividade, conforme aumento do tempo de desenvolvimento dos frutos, podendo ser observado os valores mais altos para a água extraída dos frutos colhidos com nove meses. A água extraída de frutos com oito meses foi superior às demais, reduzindo com nove meses, para os frutos colhidos ao término da estação verão. No trabalho de Resende (2007), avaliando a atividade da POD, o pesquisador observou a variação de 8,33 a 11,62 $\mathrm{U} \mathrm{min}^{-1} \mathrm{~mL}^{-1}$, em cocos verdes armazenados de zero a quarenta dias, à temperatura de $12^{\circ} \mathrm{C}$. Os valores encontrados para a água de coco avaliada neste trabalho foram superiores, fato que pode estar relacionado com a temperatura de armazenamento relatada pelo autor.

Para o aumento da atividade das enzimas oxidativas, é necessário que se tenha condições favoráveis para o desenvolvimento das reações enzimáticas, como $\mathrm{pH}$, presença de substrato, oxigênio, temperatura, entre outros fatores. Penha et al. (2005) afirmam que o pH ótimo para atuação da POD é pH na faixa de 5,5 e 7,5, condição apresentada pelas águas de coco avaliadas, o que pode ter propiciado sua ação. Quando da industrialização da água de coco verde produzida na região noroeste do Paraná, a inativação destas enzimas deve basear-se na sua atividade, pois os fatores de influência podem variar, afetando o tempo e a temperatura do processo de inativação (MURASAKI, 2005).

Os valores determinados para as avaliações 
físico-químicas estão apresentados na Tabela 3. A turbidez é a falta de transparência de um líquido, devido à presença de sólidos em suspensão. Quanto mais sólidos em suspensão, mais turva a água e maior será a turbidez (LEBER, 2001). Segundo Resende (2007), quando esses sólidos em suspensão são compostos de íons metálicos, quando a água é exposta ao ar e muito manipulada (filtragem, resfriamento, entre outros), os íons metálicos reagem com compostos fenólicos ou atuam como cofatores para enzimas, desenvolvendo a coloração da água. A coloração rósea, que é a mais comum, pode ser atribuída à presença de altas concentrações do íon magnésio. Com o excesso do mineral ferro na água de coco, a coloração desenvolvida é arroxeada, e em manganês é preta.

Pode ser observado que os valores da turbidez para a estação outono reduz com o tempo de colheita dos frutos, com diferença estatística $(\mathrm{p}>0,05)$. A água de frutos colhidos ao término da estação outono apresentou o menor valor de turbidez. Silva et al. (2009) observaram valores de 13,80 e 12,08 NTU para turbidez de água de coco de frutos, cv. Anão-Verde, produzidos no município de Trairi-CE, região Nordeste do Brasil, colhidos com sete meses de desenvolvimento, para cultivo convencional e orgânico, respectivamente, valores semelhantes à turbidez da água dos frutos cultivados no município de Umuarama, Paraná. Penha et al. (2005) apresentam que a opacidade da água de coco ocorre pela presença de lipídios na sua composição, quando o fruto está em bom estado de conservação para ser consumido.

A água de coco não apresentou diferença estatística $(p>0,05)$ para a avaliação dos valores de $\mathrm{pH}$ de frutos colhidos na estação de inverno do município de Umuarama, em diferentes estádios de desenvolvimento. $\mathrm{O}$ aumento no valor do $\mathrm{pH}$ foi observado nas demais estações climáticas deste local, conforme aumento no tempo de desenvolvimento dos frutos. De acordo com Aragão et al. (2001), o pH da água de coco varia com a idade do fruto, podendo atingir, nos primeiros cinco meses, valores de 4,7 a 4,8 , e normalmente continua resultando em valores acima de 5,00 até o final do desenvolvimento do fruto. A legislação apresenta parâmetros de valor de $\mathrm{pH}$ para água de coco processada, que varia de 4,30 a 5,40 . No caso da água de coco resfriada, pasteurizada e congelada, os valores de $\mathrm{pH}$ devem estar entre 4,30 e 4,50. Para processamento de água esterilizada, ficaram estabelecidos os valores entre 4,60 a 5,40. Para a água de coco concentrada, a legislação não apresenta valor de pH (BRASIL, 2009).

A acidez titulável (AT) da água de coco aumentou conforme o aumento do tempo de desenvolvimento dos frutos, com exceção da colheita realizada no final da estação de verão, que manteve os valores de AT entre a água de coco de frutos de diferentes estádios de desenvolvimento, não apresentando diferença estatística $(\mathrm{p}>0,05)$, sendo a água de coco com maior teor de acidez dos frutos colhidos a partir de seis meses, ao término da primavera.

Os valores de compostos fenólicos (Tabela 3) da água de coco das culturas de coqueiros, cv. AnãoVerde apresentaram diferença estatística $(\mathrm{p}<0,05)$. Os frutos, colhidos no final da estação de inverno e primavera, resultaram em aumento nos teores de compostos fenólicos da água, conforme aumento no tempo de desenvolvimento dos frutos.

Os resultados obtidos na determinação dos teores dos macroelementos presentes na água de coco podem ser visualizados na Tabela 4. Segundo Aroucha et al. (2005) e Resende (2007), os teores de minerais, na água de coco, podem variar de acordo com a cultivar, o estádio de desenvolvimento do fruto, o solo e o ambiente no qual a planta se desenvolveu.

Os fertilizantes potássicos são importantes, pois aumentam a concentração do íon potássio (K) na água de coco e acentuam a translocação de açúcares, interferindo no sabor da água do fruto. $\mathrm{O}$ $\mathrm{K}$ é o elemento presente em maior quantidade em todas as estações. Os valores apresentaram diferença significativa $(p<0,05)$ com decréscimo nos teores a partir de oito meses para água de frutos colhidos no final da estação de inverno e verão, e a partir de sete meses, na primavera e no outono. $\mathrm{O}$ cálcio $(\mathrm{Ca})$ também apresentou redução no seu valor, conforme aumento do tempo de desenvolvimento (Tabela 4), após seis meses, exceto para a água de frutos colhidos no verão, que a redução foi a partir de cinco meses. Pode ser visualizado que, na estação inverno, o Ca da água se manteve com valores superiores às outras estações, em todos os frutos, com exceção dos frutos com oito meses, colhidos na primavera e com cinco meses no verão.

Os teores de magnésio (Mg) não apresentaram diferença estatística, em nível de 5\% de probabilidade, para água de coco de frutos da colheita realizada no término da estação de inverno, e resultaram em diminuição dos teores nas demais estações climáticas. $\mathrm{O} \mathrm{Mg}$ tem sua função na ativação de reações enzimáticas, auxiliando na absorção e translocação do fósforo $(\mathrm{P})$ na planta. $\mathrm{O} \mathrm{P}$ apresentou redução dos teores na água de coco, conforme o aumento do tempo de desenvolvimento dos frutos.

Para o manganês (Mn), os resultados (Tabela 5) apresentaram diferença significativa $(\mathrm{p}<0,05)$. Para frutos colhidos no inverno, houve aumento do teor de 
Mn do quinto para o sexto mês de desenvolvimento e posterior redução até completar nove meses. Nas demais estações, os valores reduziram-se até os nove meses. $\mathrm{O}$ ferro $(\mathrm{Fe})$ não apresentou diferença para os frutos colhidos após o verão, não sendo detectados pelo limite da determinação os teores para os frutos colhidos com oito e nove meses. O cobre $(\mathrm{Cu})$ só foi detectado para cocos da estação verão, com aparente redução nos teores, conforme aumento do estádio de desenvolvimento. $\mathrm{O}$ zinco $(\mathrm{Zn})$ presente também sofreu redução em seus teores, conforme aumento do tempo de desenvolvimento dos frutos, com diferença estatística $(\mathrm{p}<0,05)$.

TABELA 1 - Características do solo da plantação de coqueiros, cv. Anão-Verde, Umuarama, Paraná.

\begin{tabular}{lcccc}
\hline \multirow{2}{*}{\multicolumn{1}{c}{ Características }} & \multicolumn{3}{c}{ Copa } & Profundidade \\
\cline { 2 - 5 } & $0-20 \mathrm{~cm}$ & $20-40 \mathrm{~cm}$ & $0-20 \mathrm{~cm}$ & $20-40 \mathrm{~cm}$ \\
\cline { 2 - 5 } Areia (\%) & 89,00 & 86,00 & 88,00 & 90,00 \\
Argila (\%) & 8,00 & 10,00 & 8,40 & 6,00 \\
Silte (\%) & 3,00 & 4,00 & 3,60 & 4,00 \\
\hline pH CaCl & 4,43 & 4,07 & 4,26 & 4,25 \\
pH H${ }_{2} \mathrm{O}$ & 5,42 & 5,03 & 5,24 & 5,23 \\
pH SMP & 6,29 & 6,38 & 6,50 & 6,63 \\
Alumínio $\left(\mathrm{cmolc} \mathrm{dm}^{-3}\right)$ & 0,17 & 0,30 & 0,22 & 0,22 \\
Hidrogênio $\left(\mathrm{cmolc} \mathrm{dm}^{-3}\right)$ & 3,83 & 3,44 & 3,20 & 2,89 \\
Al + H $\left(\mathrm{cmolc} \mathrm{dm}^{-3}\right)$ & 4,00 & 3,74 & 3,42 & 3,11 \\
Matéria Orgânica $\left(\mathrm{g} \mathrm{kg}^{-1}\right)$ & 7,75 & 7,55 & 6,63 & 6,86 \\
Fósforo $\left(\mathrm{mg} \mathrm{dm}^{-3}\right)$ & 68,79 & 68,79 & 16,15 & 8,10 \\
Cálcio $\left(\mathrm{mg} \mathrm{dm}^{-3}\right)$ & 0,71 & 0,30 & 0,31 & 0,35 \\
Magnésio $\left(\mathrm{mg} \mathrm{dm}^{-3}\right)$ & 0,17 & 0,13 & 0,11 & 0,12 \\
Potássio $\left(\mathrm{mg} \mathrm{dm}^{-3}\right)$ & 0,18 & 0,16 & 0,06 & 0,06 \\
Cobre $\left(\mathrm{mg} \mathrm{dm}^{-3}\right)$ & 2,70 & 2,00 & 2,00 & 1,70 \\
Zinco $\left(\mathrm{mg} \mathrm{dm}^{-3}\right)$ & 6,46 & 4,01 & 5,94 & 3,29 \\
Ferro $\left(\mathrm{mg} \mathrm{dm}^{-3}\right)$ & 43,35 & 58,52 & 28,24 & 32,44 \\
Manganês $\left(\mathrm{mg} \mathrm{dm}^{-3}\right)$ & 28,36 & 31,78 & 42,28 & 35,71 \\
Boro $\left(\mathrm{mg} \mathrm{dm}^{-3}\right)$ & 0,38 & 0,37 & 0,16 & 0,19 \\
\hline
\end{tabular}

TABELA 2 - Períodos de colheitas dos cocos verdes.

\begin{tabular}{lcc}
\hline Estação climática & Período & Datas de colheita \\
\hline Inverno & $21-06-2009$ a 23-09-2009 & $20-09-2009$ \\
Primavera & $23-09-2009$ a 20-12-2009 & $19-12-2009$ \\
Verão & $21-12-2009$ a 19-03-2010 & $19-03-2010$ \\
Outono & $20-03-2010$ a 20-06-2010 & $19-06-2010$ \\
\hline
\end{tabular}


TABELA 3 - Avaliações físico-químicas da água de coco, cv. Anão-Verde, de frutos colhidos em diferentes estádios de desenvolvimento e estação climática.

\begin{tabular}{|c|c|c|c|c|c|}
\hline \multirow{3}{*}{ Período } & \multicolumn{5}{|c|}{ Estádios de desenvolvimento (meses) } \\
\hline & 5 & 6 & 7 & 8 & 9 \\
\hline & \multicolumn{5}{|c|}{ Turbidez (NTU) } \\
\hline Inverno & $12,73 \mathrm{abAB}$ & $12,33 \mathrm{abB}$ & $11,45 \mathrm{bAB}$ & $13,15 \mathrm{abA}$ & $14,30 \mathrm{aAB}$ \\
\hline Primavera & 11,16bB & $10,28 \mathrm{cC}$ & $10,14 \mathrm{cB}$ & $12,56 \mathrm{abA}$ & $15,16 \mathrm{aA}$ \\
\hline Verão & $12,30 \mathrm{bAB}$ & $13,75 \mathrm{aA}$ & $12,46 \mathrm{bA}$ & $11,53 \mathrm{bA}$ & $13,32 \mathrm{abBC}$ \\
\hline \multirow[t]{2}{*}{ Outono } & $13,50 \mathrm{abA}$ & $11,82 \mathrm{bcB}$ & $10,72 \mathrm{bcB}$ & $10,99 \mathrm{bcA}$ & $10,76 \mathrm{cC}$ \\
\hline & \multicolumn{5}{|c|}{$\mathrm{pH}$} \\
\hline Inverno & $4,66 \mathrm{aA}$ & $4,91 \mathrm{aB}$ & $4,65 \mathrm{aB}$ & $4,97 \mathrm{aAB}$ & $5,35 \mathrm{aA}$ \\
\hline Primavera & $4,82 \mathrm{aA}$ & 4,77abB & 4,75abAB & $4,71 b \mathrm{~b}$ & $4,73 \mathrm{abC}$ \\
\hline Verão & $4,98 \mathrm{bA}$ & $5,29 \mathrm{aA}$ & $5,23 \mathrm{aA}$ & $5,12 \mathrm{abA}$ & $5,12 \mathrm{abB}$ \\
\hline \multirow[t]{2}{*}{ Outono } & $4,88 \mathrm{abA}$ & 4,90abB & $4,81 \mathrm{bAB}$ & $4,80 \mathrm{bBC}$ & $5,01 \mathrm{aB}$ \\
\hline & \multicolumn{5}{|c|}{ Acidez Titulável (g ácido cítrico $100 \mathrm{~mL}^{-1}$ ) } \\
\hline Inverno & $0,057 \mathrm{bC}$ & $0,063 \mathrm{abA}$ & $0,083 \mathrm{aAB}$ & $0,070 \mathrm{aB}$ & $0,083 \mathrm{aA}$ \\
\hline Primavera & $0,058 \mathrm{cC}$ & $0,070 \mathrm{bcA}$ & $0,085 \mathrm{bA}$ & $0,113 \mathrm{aA}$ & $0,068 \mathrm{bcA}$ \\
\hline Verão & $0,068 \mathrm{aA}$ & $0,073 \mathrm{aA}$ & $0,078 \mathrm{aB}$ & $0,093 \mathrm{aAB}$ & $0,088 \mathrm{aA}$ \\
\hline \multirow[t]{2}{*}{ Outono } & $0,062 \mathrm{bB}$ & $0,071 \mathrm{bA}$ & $0,085 \mathrm{aA}$ & $0,083 \mathrm{aB}$ & $0,091 \mathrm{aA}$ \\
\hline & \multicolumn{5}{|c|}{ Compostos Fenólicos (mg de ácido gálico $100 \mathrm{~mL}^{-1}$ ) } \\
\hline Inverno & $4,29 \mathrm{bA}$ & 3,98bA & 4,19bA & $5,92 \mathrm{aA}$ & $5,77 \mathrm{aA}$ \\
\hline Primavera & $3,87 \mathrm{cA}$ & $4,32 \mathrm{bcA}$ & $3,78 \mathrm{cA}$ & $5,36 \mathrm{abA}$ & $5,91 \mathrm{aA}$ \\
\hline Verão & $3,02 \mathrm{abB}$ & $3,12 \mathrm{aB}$ & $2,93 \mathrm{abB}$ & $2,65 \mathrm{bcB}$ & $2,38 \mathrm{cC}$ \\
\hline Outono & $3,01 \mathrm{abB}$ & $2,88 \mathrm{bB}$ & $3,01 \mathrm{abB}$ & $3,24 \mathrm{aB}$ & $3,03 \mathrm{abB}$ \\
\hline
\end{tabular}

*Médias seguidas pela mesma letra minúscula, na linha, e maiúscula, na coluna, não diferem significativamente, pelo teste de Tukey $(\mathrm{p}>0,05)$.

Safra 2009/2010

TABELA 4 - Macroelementos minerais da água de coco, cv Anão-Verde, de frutos colhidos em diferentes estádios de desenvolvimento e estação climática.

\begin{tabular}{lccccc}
\hline \multirow{2}{*}{ Período } & \multicolumn{5}{c}{ Estádios de desenvolvimento (meses) } \\
\cline { 2 - 6 } & 5 & 6 & 7 & 8 \\
\cline { 2 - 6 } & \multicolumn{5}{c}{ Potássio $\left(\mathrm{mg} \mathrm{L}^{-1}\right)$} \\
\hline Inverno & $2261,10 \mathrm{aB}$ & $2294,10 \mathrm{aA}$ & $2062,10 \mathrm{aA}$ & $1683,80 \mathrm{bB}$ & $1667,10 \mathrm{bA}$ \\
Primavera & $2038,30 \mathrm{aB}$ & $1947,35 \mathrm{aB}$ & $1685,85 \mathrm{bC}$ & $1708,25 \mathrm{bB}$ & $1602,93 \mathrm{bA}$ \\
Verão & $2677,33 \mathrm{aA}$ & $2363,17 \mathrm{bA}$ & $2109,24 \mathrm{cA}$ & $1869,12 \mathrm{dA}$ & $1679,14 \mathrm{dA}$ \\
Outono & $2217,01 \mathrm{aB}$ & $2110,68 \mathrm{aAB}$ & $1899,03 \mathrm{bB}$ & $1729,54 \mathrm{cAB}$ & $1573,48 \mathrm{dA}$ \\
\hline \multicolumn{5}{c}{ Cálcio $\left(\mathrm{mg} \mathrm{L}^{-1}\right)$} \\
\hline Inverno & $201,37 \mathrm{bA}$ & $233,33 \mathrm{aA}$ & $205,45 \mathrm{abA}$ & $159,97 \mathrm{cA}$ & $97,58 \mathrm{dA}$ \\
Primavera & $117,73 \mathrm{cB}$ & $153,60 \mathrm{abBC}$ & $176,08 \mathrm{aB}$ & $137,62 \mathrm{bcA}$ & $67,36 \mathrm{dC}$ \\
Verão & $193,71 \mathrm{aA}$ & $134,87 \mathrm{bC}$ & $115,67 \mathrm{cC}$ & $93,50 \mathrm{~dB}$ & $66,52 \mathrm{eC}$ \\
Outono & $146,63 \mathrm{aB}$ & $164,48 \mathrm{aB}$ & $121,55 \mathrm{bC}$ & $112,29 \mathrm{bB}$ & $82,03 \mathrm{cB}$ \\
\hline \multicolumn{5}{c}{ Magnésio $\left(\mathrm{mg} \mathrm{L}^{-1}\right)$} \\
\hline Inverno & $105,66 \mathrm{aC}$ & $102,21 \mathrm{aB}$ & $138,64 \mathrm{aA}$ & $124,94 \mathrm{aA}$ \\
Primavera & $141,31 \mathrm{abB}$ & $131,28 \mathrm{bA}$ & $149,18 \mathrm{aA}$ & $112,97 \mathrm{cAB}$ & $140,29 \mathrm{aA}$ \\
Verão & $146,20 \mathrm{aAB}$ & $121,13 \mathrm{bA}$ & $90,36 \mathrm{cB}$ & $69,91 \mathrm{dC}$ & $50,12 \mathrm{~dB}$ \\
Outono & $156,36 \mathrm{aA}$ & $131,20 \mathrm{bA}$ & $121,17 \mathrm{bAB}$ & $90,36 \mathrm{cBC}$ & $89,59 \mathrm{cB}$ \\
\hline \multicolumn{5}{c}{ Fósforo $\left(\mathrm{mg} \mathrm{L}^{-1}\right)$} \\
Inverno & $31,03 \mathrm{abB}$ & $31,45 \mathrm{abC}$ & $38,12 \mathrm{aA}$ & $24,52 \mathrm{bcC}$ & $18,62 \mathrm{cB}$ \\
Primavera & $42,29 \mathrm{abA}$ & $44,83 \mathrm{aA}$ & $40,29 \mathrm{bA}$ & $28,56 \mathrm{cB}$ & $17,64 \mathrm{~dB}$ \\
Verão & $42,50 \mathrm{aA}$ & $36,66 \mathrm{bB}$ & $34,66 \mathrm{bA}$ & $32,57 \mathrm{bA}$ & $24,87 \mathrm{cA}$ \\
Outono & $42,29 \mathrm{abA}$ & $44,83 \mathrm{aA}$ & $40,29 \mathrm{bA}$ & $28,56 \mathrm{cB}$ & $17,64 \mathrm{~dB}$ \\
\hline
\end{tabular}

*Médias seguidas pela mesma letra minúscula, na linha, e maiúscula, na coluna, não diferem significativamente, pelo teste de Tukey $(\mathrm{p}>0,05)$.

Safra 2009/2010 
TABELA 5 - Microelementos minerais da água de coco, cv Anão-Verde, de frutos colhidos em diferentes estádios de desenvolvimento e estação climática.

\begin{tabular}{lccccc}
\hline \multirow{2}{*}{ Período } & \multicolumn{5}{c}{ Estádios de desenvolvimento (meses) } \\
\cline { 2 - 6 } & 5 & 6 & 7 & 8 & 9 \\
\hline \multicolumn{5}{c}{ Manganês $\left(\mathrm{mg} \mathrm{L}^{-1}\right)$} \\
Inverno & $3,63 \mathrm{bA} *$ & $4,39 \mathrm{aA}$ & $3,41 \mathrm{bA}$ & $3,03 \mathrm{bA}$ & $2,26 \mathrm{cA}$ \\
Primavera & $3,32 \mathrm{aA}$ & $3,02 \mathrm{bB}$ & $2,62 \mathrm{cB}$ & $2,05 \mathrm{~dB}$ & $1,74 \mathrm{eB}$ \\
Verão & $3,20 \mathrm{aA}$ & $2,97 \mathrm{aB}$ & $2,57 \mathrm{bB}$ & $2,10 \mathrm{cB}$ & $1,66 \mathrm{~dB}$ \\
Outono & $3,74 \mathrm{aA}$ & $3,16 \mathrm{bB}$ & $2,60 \mathrm{cB}$ & $2,19 \mathrm{~dB}$ & $1,68 \mathrm{eB}$ \\
\hline \multicolumn{5}{c}{ Ferro $\left(\mathrm{mg} \mathrm{L}^{-1}\right)$} \\
\hline Inverno & $0,38 \mathrm{bA}$ & $0,72 \mathrm{aA}$ & $0,87 \mathrm{aA}$ & $0,82 \mathrm{aA}$ & $0,21 \mathrm{cA}$ \\
Primavera & $0,19 \mathrm{bcB}$ & $0,26 \mathrm{abB}$ & $0,31 \mathrm{aB}$ & $0,19 \mathrm{bcB}$ & $0,11 \mathrm{~dB}$ \\
Verão & $0,21 \mathrm{aB}$ & $0,14 \mathrm{aB}$ & $0,19 \mathrm{aC}$ & $<0,01$ & $<0,01$ \\
Outono & $0,23 \mathrm{abB}$ & $0,24 \mathrm{abB}$ & $0,28 \mathrm{aBC}$ & $0,19 \mathrm{bcB}$ & $0,11 \mathrm{cB}$ \\
\hline \multicolumn{5}{c}{ Cobre $\left(\mathrm{mg} \mathrm{L}^{-1}\right)$} \\
\hline Inverno & $<0,01$ & $<0,01$ & $<0,01$ & $<0,01$ & $<0,01$ \\
Primavera & $<0,01$ & $<0,01$ & $<0,01$ & $<0,01$ & $<0,01$ \\
Verão & $0,27 \mathrm{a}$ & $0,29 \mathrm{a}$ & $0,18 \mathrm{~b}$ & $0,16 \mathrm{~b}$ & $0,13 \mathrm{~b}$ \\
Outono & $<0,01$ & $<0,01$ & $<0,01$ & $<0,01$ & $<0,01$ \\
\hline \multicolumn{5}{c}{ Zinco (mg L-1) } \\
Inverno & $0,46 \mathrm{aA}$ & $0,44 \mathrm{abA}$ & $0,52 \mathrm{aA}$ & $0,38 \mathrm{abA}$ & $0,25 \mathrm{bA}$ \\
Primavera & $0,47 \mathrm{aA}$ & $0,38 \mathrm{aA}$ & $0,29 \mathrm{aB}$ & $0,22 \mathrm{aBC}$ & $0,17 \mathrm{bB}$ \\
Verão & $0,57 \mathrm{aA}$ & $0,41 \mathrm{bA}$ & $0,35 \mathrm{bB}$ & $0,27 \mathrm{cB}$ & $0,16 \mathrm{~dB}$ \\
Outono & $0,47 \mathrm{aA}$ & $0,41 \mathrm{aA}$ & $0,30 \mathrm{bB}$ & $0,19 \mathrm{cC}$ & $0,14 \mathrm{cB}$ \\
\hline
\end{tabular}

*Médias seguidas pela mesma letra minúscula, na linha, e maiúscula, na coluna, não diferem significativamente, pelo teste de Tukey (p>0,05). Safra 2009/2010.

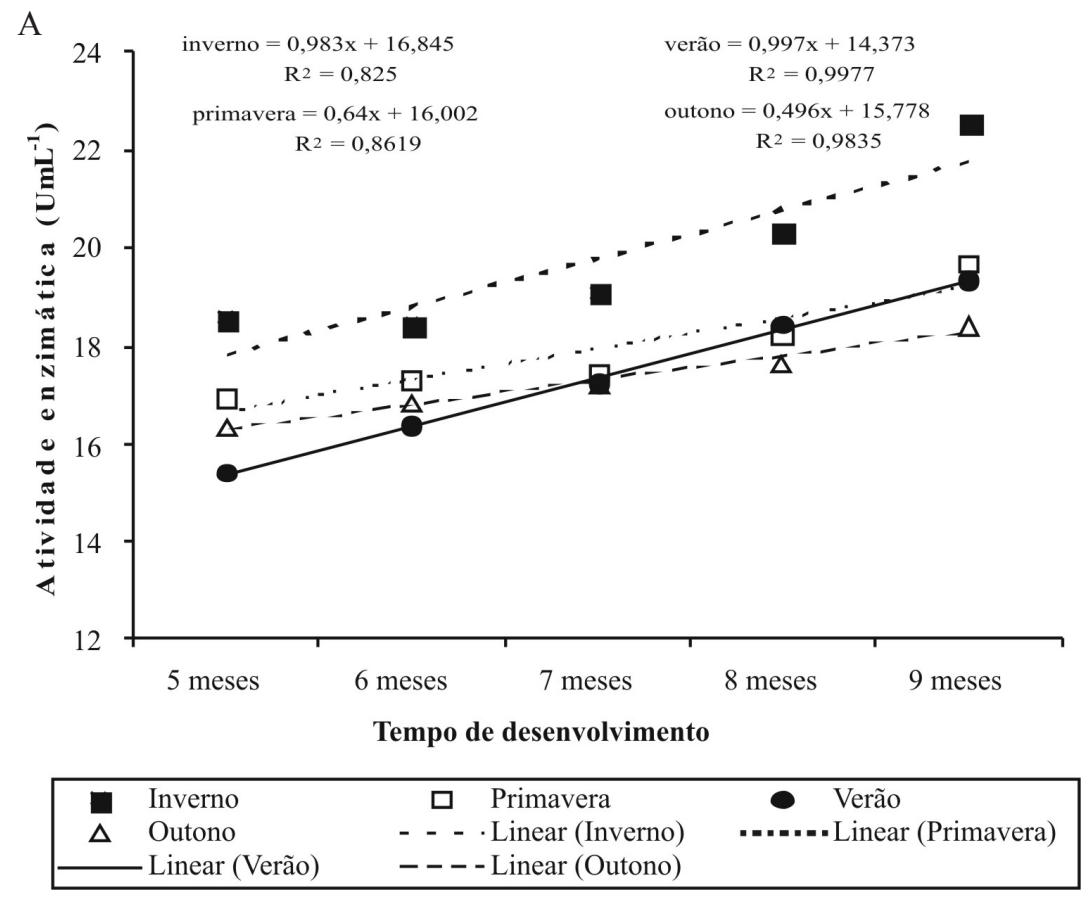


continuação..

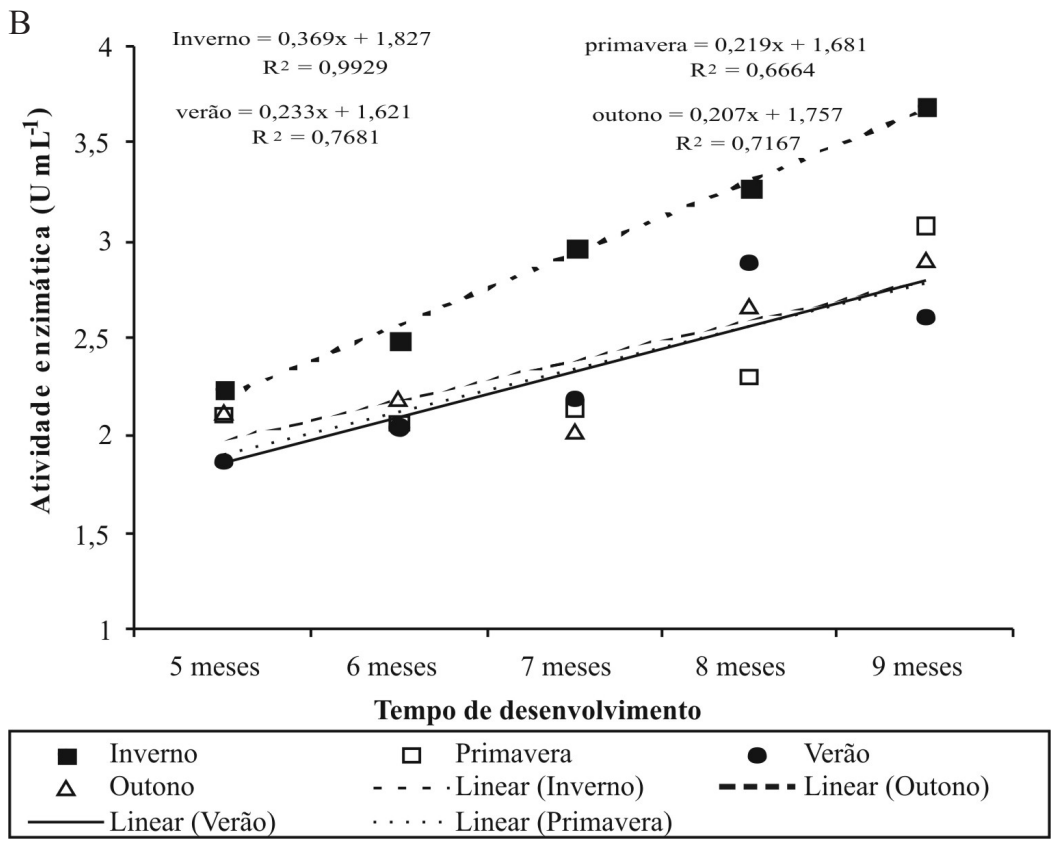

FIGURA 1 - Evolução da atividade da polifenoloxidase (PPO) (A) e peroxidase (POD) (B) de água de coco, cv. Anão-Verde, de frutos colhidos em diferentes estádios de desenvolvimento e estações climáticas.

\section{CONCLUSÃO}

As atividades das enzimas PPO e POD da água de coco aumentam com o aumento do tempo de desenvolvimento dos frutos. Os maiores valores desta atividade são observados na estação de inverno. A turbidez varia conforme o estádio de desenvolvimento, sendo que há redução para os frutos colhidos no outono. A acidez da água de coco aumentou conforme o aumento do tempo de colheita dos frutos para todas as estações. Os teores de compostos fenólicos também aumentam com o estádio de desenvolvimento dos cocos. O potássio é o elemento mineral presente em maior concentração nas águas dos frutos avaliados. O cobre só é detectado na água de coco na estação do verão.

\section{REFERÊNCIAS}

ABREU, L. F.; FARIA, J. A. F. Influência da temperatura e do ácido ascórbico sobre a estabilidade físicoquímica e atividade enzimática da água de coco (Cocos nucifera L.) acondicionada assepticamente. Ciência e Tecnologia de Alimentos, Campinas, v. 27 , n. 2, p. 226-232, 2007.

ARAGÃO, F. B.; LOIOLA, C. M.; CAMBUI, E. V. F.; ARAGÃO, W. M. Produção de água de coco de cultivares de coqueiro verde. Aracaju: EMBRAPA, 2005. p. 1-2. (Comunicado Técnico, 42)

ARAGÃO, W. M.; ISBERNER, I. V.; CRUZ, E. M. de. O. Água de coco. Aracaju: Embrapa - CNPCo, 2001. 32p. (Documentos, 24)

AROUCHA, E. M. M.; SOUZA, C. L. M.; AROUCHA, M. C. M.; VIANNI, R. Características físicas e químicas da água de coco Anão-Verde e AnãoVermelho em diferentes estádios de maturação.

Caatinga, Mossoró, v. 18, n. 2, p. 82-87, 2005. 
BRASIL. Ministério da Agricultura, Pecuária e Abastecimento. Instrução normativa n.27, de 22 de julho de 2009. Estabelece os procedimentos mínimos de controle higiênico-sanitário, padrões de identidade e características mínimas de qualidade gerais para a água de coco. Diário Oficial da União, Brasília, DF, 23 jul. 2009. Seção 1, p.6.

BUCIC-KOJIC, A.; PLANINIC, M.; TOMAS, S.; BILIC, M.; VALIC, D. Study of solid-liquid extraction kinetics of total polyphenols from grape seeds. Journal of Food Engineering, Oxford, v. 81, p. 236-242, 2007.

CABRAL, L. M. C.; PENHA, E. M.; MATTA, V. M. Água de coco verde refrigerada. Brasília: Embrapa Informação Tecnológica, 2005. p. -34.

CONCELlÓN, A.; AÑON, M.C.; CHAVES, A.R. Characterization and changes in polyphenol oxidase from eggplant fruit (Solanum melongena L.) during storage at low temperature. Food Chemistry, Oxford, v. 88, p. 17-24, 2004.

DUARTE, A. C. P.; COELHO, M. A. Z.; LEITE, S. G. F. Identification of peroxidase and tyrosinase in Green coconut water. Ciencia y Tecnología Alimentaria, Reynosa, v.3, n.5, p. 266-270, 2002.

IBGE. Instituto Brasileiro de Geografia e Estatística. Estados. Produção de coco da baía. Paraná, 2008. Disponível em: $<$ http://www.ibge.gov.br/estadosat/ temas.php?sigla=pr\&tema=lavourapermanen $\underline{\text { te2008 }}$ >. Acesso em: 15 out. 2010.

ITAL - Instituto de Tecnologia de Alimentos. Análises químicas de alimentos. Campinas, 1990. p. 60. (Manual Técnico)

KWIATKOWSKI, A.; CLEMENTE, E. ; SCARCELLI, A.; VIDA, J. B. Quality of coconut water 'in natura' belonging to green dwarf fruit variety in different stages of development, in plantation on the northwest area of Paraná, Brazil. Journal of Food, Agriculture \& Environment, Helsink, v. 6, n.1, p. 90-93, 2008.

LEBER, A. S. M. L. Avaliação da estabilidade de água de coco (Cocos nucifera) em garrafas de polietileno tereftalato (PET) estocadas congelada e refrigerada. 2001. 151f. Dissertação (Mestrado em Tecnologia de Alimentos) - Universidade Estadual de Campinas, Campinas, 2001.
MACIEL, V. T.; GOMES FILHO, E.; ALVES, R. E.; FARIAS, J. M.; SOUZA, H. U. Caracterização física dos frutos de seis cultivares de coqueiro Anão em diferentes estádios de desenvolvimento. Revista Brasileira de Ciências Agrárias, Recife, v. 4, n. 4, p. 395-398, 2009.

MURASAKI, N. C. Cinética da inativação térmica da peroxidase e da polifenoloxidase presentes na água de coco verde por processo térmico contínuo. 2005. 78f. Dissertação (Mestrado em Engenharia) Escola Politécnica da Universidade de São Paulo, São Paulo, 2005.

PAVAN, M. A.; BLOCH, M. F.; ZEMPULSKI, H. C.; MIYAZAWA, M.; ZOCOLER, D. C. Manual de análise química do solo e controle de qualidade. Londrina: IAPAR, 1992, p. 40. (Circular Técnica, 76)

PENHA, E. M.; CABRAL, L. M. C.; MATTA, V. M. Água de coco. In: VENTURNI FILHO, W. G. (Coord.). Tecnologia de bebidas: matéria-prima, processamento, BPF/APPCC e legislação. São Paulo: Edgar Blucher, 2005. p. 103-118.

REICHEL, M.; CARLE, R.; SRUAMSIRI, P.; NEIDHART, S. Influence of harvest maturity on quality and shelf-life of litchi fruit (Litchi chinensis Sonn.). Postharvest Biology and Technology, Amsterdam, v. 57, p. 162-175, 2010.

RESENDE, J. M. Revestimentos biodegradáveis para conservação do coco 'Anão-Verde'. 2007. 200 f. Tese (Doutorado em Engenharia Agrícola) Universidade Estadual de Campinas. Faculdade de Engenharia Agrícola, Campinas, 2007.

RUENROENGKLIN, N.; SUN, J.; SHI, J., XUE, S.J.; JIANG, Y. Role of endogenous and exogenous phenolics in litchi anthocyanin degradation caused by polyphenol oxidase. Food Chemistry, Oxford, v. 115 , p. 1253-1256, 2009.

\section{SAS. Statistical analyses system. Cary, 2001.}

SILVA, S. L. V.; ALVES, R. E.; FIGUEIREDO, R. W.; MACIEL, V. T.; FARIAS, J. M.; AQUINO, A. R. L. Características físicas, físico-químicas e sensoriais da água de frutos de coqueiro Anão-verde oriundo de produção convencional e orgânica. Ciência e Agrotecnologia, Lavras, v. 33, n. 4, p. 1079-1084, 2009. 